\title{
Development of simulators in medical education
}

by George H. Buck

\section{SUMMARY}

The historical development of simulators is presented in respect to their application in medical training. Simulators allow, to some extent, practical training without any inconvenience for patients. The earliest simulators in the history of medicine were the obstetrical manikins introduced towards 1700 by father and son Grégoire of Paris and primarily intended for the instruction of lay people, i.e. midwives. Their further development is followed up to contemporary models of highly specialized use.

Since 1960 simulators are more and more used for the training of doctors, nurses and laymen in resuscitation techniques. In combination with computers, high-fidelity simulators were created which, e.g., react to anaesthetics like real human beings. Conclusions about future developments and uses of simulators in medical education, in view of their history, are provided.

A perennial problem facing medical educators is to teach concepts and practical information in such ways that the student can transfer the acquired knowledge successfully to an actual clinical situation. In addition to lectures, static models, demonstrations, recordings, slides, rôle-playing, laboratory exercises and periods of supervised clinical practice, some students are exposed to mechanical, electro-mechanical and electronic devices (some computer-controlled) that attempt to reproduce, with varying degrees of accuracy and realism, particular processes, problems or conditions in a patient. This equipment, besides presenting information in the manner of a static model, such as one of a human body that can be disassembled, or a silicone model of a breast, also requires the student to interact with it. Furthermore, the action of the student results in the equipment producing some sort of reaction, either by means of itself or by means of an operator. Such apparatus is generally referred to as simulators ${ }^{1}$. The term is vague, however, since what constitutes a simulator in medical education may range from a computer program that reproduces bodily 
processes diagrammatically by means of audiovisual techniques, to a robotic manikin that incorporates manifold physical characteristics including some bodily processes. The term fidelity can be applied as a descriptive qualifier to simulators. The greater the number of attributes the device reproduces realistically, the greater the overall fidelity of the simulator. There are three main components that comprise fidelity. They are completeness of the simulation, realism of the apparatus or situation, and the timing of the event or activity $^{2}$.

It may be a popular impression that simulators are recent inventions, and that their application to medical education is contemporaneous with the advent of modern computer technology. There is evidence to show, however, that simulators have existed since ancient times, and that some were used for practical medical instruction as early as the seventeenth century A.D. ${ }^{3}$

\section{Pedagogical basis}

The psychologists Bandura and Walters cite anthropological studies as well as their own findings to support the contention that modeling, simulations, observational learning and imitative learning are accepted methods of pedagogy throughout most cultures at the present time. They also contend that such learning methods have existed for a considerable time ${ }^{4}$. There are many pedagogical factors common among simulators which may be considered advantageous: inter alia, transfer of learning, practice, feedback, controllable processes and trial and error.

Transfer of learning is the idea that concepts which are learned from an artificial situation (including simulations) can be transferred and applied in an actual situation. For example, a pilot might first learn from a simulator how to escape from a spin and then would be able to perform the maneuver correctly in a real aircraft. A prevalent assumption in education is that proficiency of performance usually increases with repeated practice ${ }^{5}$. By their nature, most simulations permit repeated practice. Feedback, or knowledge of results, is one of the most important pedagogical considerations. Unless students are made aware of the consequences of their actions, no learning takes place. This is one of the basic premises of behaviouristic learning, as articulated by psychologists such as B. F. Skinner ${ }^{6}$. A controllable process is one in which the concepts to be learned are selected and sequenced. By controlling what a simulation presents, for example, it may be possible to 
have students attend to a particular concept that might be under consideration at a particular time. Such control is usually not possible in an actual situation or in some contrived situations such as students or actors who mimic attributes of patients with particular conditions or diseases. Trial and error learning may also be performed with a simulator without exposing an actual patient, the apparatus or the participants to any risk. Through trial and error purposeful exploration, insight and experimentation can occur. We shall now consider some evidence that indicates that many of these factors were recognized in the past, and that they were addressed through formal pedagogical means, including simulations.

\section{Antecedent use of simulators}

Some of the first simulators, developed by the ancient Greeks, were intended to be used for instruction in Stoic philosophy. It seems that a concrete representation of an abstract concept was thought to be superior pedagogically to a solely verbal description. Through this method the student can observe a simulation of the supposed actual circumstance and, it is anticipated, acquire an understanding of the concept ${ }^{7}$. While some ancient simulators were mechanically elaborate, there is no evidence to suggest that any were used as instructional aids in medicine at that time.

Later pedagogical methods usually had no provision for simulators, had they existed. In the mediæval period, the preferred method of instruction for most subjects was lecturing supplemented with books ${ }^{8}$. Although some doctors such as Mondino de'Luzzi (1275-1326) employed cadavers to supplement their lectures, the use of simulators either for individual practice or for demonstrating difficult procedures or rare conditions to classes does not appear to have been considered. The availability of suitable natural objects (cadavers and animals) as well as the existence of anatomical models likely satisfied the limited need for instructional materials during these periods ${ }^{9}$.

\section{Obstetric simulators}

The situation changed by the mid-sixteenth century when concern was focused upon the apparent causal relationship between the use of midwives and a high infant mortality rate ${ }^{10}$. Although many doctors of that time 
possessed sufficient knowledge to be of greater assistance in child birth than most midwives, it was considered largely inappropriate for doctors, nearly all of whom were males, to work in an area generally considered to be the realm of women ${ }^{11}$. As well, the practice of obstetrics suffered a low social status at that time ${ }^{12}$. The large number of children who died or were maimed by improper handling during parturition, as well as complications to or fatality among the mothers caused by midwives, led to the introduction of licensing laws in European countries as early as the late sixteenth century ${ }^{13}$. The need for midwives who were properly trained induced some doctors to offer special courses for practicing midwives, as well as for women who desired to become midwives. Most of these first attempts consisted of lectures supplemented with illustrations ${ }^{14}$. The failure of this pedagogical approach to effect widespread improvement in the way midwives performed is a probable reason for the development of obstetrical simulators. One of the first of such simulators was developed in France by one or both of the Drs. Grégoire. This father and son team, noted for their positive reputation as teachers of midwifery, taught during the late seventeenth and early eighteenth centuries in Paris primarily ${ }^{15}$.

\section{The Grégoires' simulator}

The Grégoires created a manikin which was intended to simulate the abdomen of a human female. This contrivance is sometimes referred to as a phantom. The simulator could reproduce, in a crude manner, the birth of a child and some related complications of a sort that would require a trained professional to rectify successfully. Although there are no known illustrations of the Grégoires' device, it is possible to obtain a rudimentary understanding of it from surviving descriptions. The apparatus consisted of a human pelvis contained in a basket-work frame. The pelvis and the immediate area were covered with an oil-skin, while the remaining portions were covered with a coarse cloth. The oil-skin was probably used to simulate the genitalia. Real fœtuses, likely preserved by some means, were used in conjunction with the manikin ${ }^{16}$. By manipulating a fœtus within the manikin it would be possible to simulate a variety of birthing complications. The midwives could receive practical hands-on experience with this method. If an error was made, the procedure could be halted immediately and the mistake corrected. 
This method of instruction has several distinct advantages over training with real births. First, trainees may make mistakes with the simulator without placing an actual woman or a live fœtus in peril. Second, trainees can be shown complications that they might otherwise not observe while attending an actual birth. Third, the simulation can be stopped at any point and it can be repeated; the simulation does not have to proceed in real time. Fourth, distraction is kept to a minimum, since the trainee needs to concentrate only on the simulation and the instructor, not to irrelevant behavior of the mother. Fifth, social taboos related to observing women's genitalia are not violated. It may be asked why such a simulation was used at that time when none seem to have been used in earlier medical instruction.

Although it is possible for surgeons to obtain practice by operating on animals, a similar arrangement is not readily available for midwives. While it is not difficult to have a large number of student surgeons present at a scheduled operation, it is not as easy to assemble a number of midwives to observe a birth, given that births cannot usually be scheduled to a precise time. A simulation, in this case, is ideal. In this instance, the simulator fulfilled an evident need that could not be satisfied in any other way.

Schlebecker describes four essential elements which are required before a technological invention can occur: (1) accumulated knowledge; (2) evident need; (3) economic possibility; (4) cultural and social acceptability ${ }^{17}$. The Grégoires' manikin satisfied all four elements. The manikin itself was technologically unsophisticated: there was evidently sufficient accumulated knowledge and technical skill to fabricate it. There was evident need, as indicated in the previous paragraph. No components of the simulator were expensive, and so it was economically feasible to construct. Social acceptability did not appear to be a major problem, although some midwives rejected the pedagogical principle of learning from an inanimate object instead of from an actual woman ${ }^{18}$.

The Grégoires' simulator likely' had a low level of fidelity, since some individuals who observed it in use thought that it did not resemble a human being at all, "'tis so rude a work that a common pelvis stuck into a whale without any embellishment would be as like nature as this machine which has been so much admired" 19 . In spite of low fidelity, it did function as an effective instructional device. Although the Grégoires' simulator was successful despite its lack of realism, at least one surgeon was concerned for fear that the information learned from such a crude device could not be transferred readily to an actual human being ${ }^{20}$. 


\section{Smellie's simulator}

William Smellie (1697-1763) was an English surgeon and medical practitioner who developed several obstetrical instruments, and who is also noted for being a foremost teacher of midwifery in the eighteenth century ${ }^{21}$. Smellie, who studied obstetrics under the younger Dr. Grégoire, developed more elaborate simulators to assist with instruction in obstetrics ${ }^{22}$. Instead of using a basket-work frame, Smellie used bones from the skeleton of a human being. The covering material was smooth leather and the interior spaces were stuffed with "an agreeable soft substance" 23 . A uterus that could be made to dilate and contract was also provided ${ }^{24}$. It is not certain what material comprised the uterus. Some means of simulating amniotic fluid and blood was probably present as well, since Mrs. Nihell, a midwife who did not approve of Smellie's simulators, mentions a bladder:

"This bladder was stopped with a cork, to which was fastened a string of packthread, to tap it occasionally and demonstrate in a palpable manner the flowing of red-colored waters" 25 .

As well as increasing the fidelity of the simulator, the inclusion of simulated amniotic fluid provides a cue as to the progress of the simulation. The presence of amniotic fluid would provide tangible evidence that the amniotic sac was broken and that the birth of the child was imminent. The release of the fluid was under the control of the instructor operating the simulator. This action is an example of a controllable process.

Unlike the Grégoires' use of real fœtuses, Smellie constructed artificial fœtuses from wood and some unknown elastic substance, possibly rubber. One of Smellie's students described the fake fœtuses in this manner:

"The Children for these machines [simulators] are likewise excellently contrived, they having all the Motions of the Joints. Their Craniums are so formed as to give way to any Force exerted, and are so Elastik [sic] that the Pressure is no sooner taken off than they return to their natural Equalities."

Smellie's concern with the fidelity did not end there. Artificial afterbirth composed of different varieties of leather was also used, perhaps to simulate the condition of a retained placenta ${ }^{26}$. Smellie constructed at least three separate simulators ${ }^{27}$. It is not certain because of insufficient descriptions, whether they were identical or whether each was designed to simulate a particular set of problems.

The higher fidelity of Smellie's simulators did not alter the concepts being taught, but the more realistic appearance of the devices seems to have been 
intended to facilitate the transfer of learning. Although Smellie's devices were well received by most lay people and by some other physicians, there were critics. In addition to the criticisms made by Mrs. Nihell, mentioned previously, others considered the simulators to be so unrealistic that no learning would take place. For example, a contemporary of Smellie's, Dr. William Douglas, states:

"Instead of a Child you make use of little stuffed Babies, which have rather amused than instructed your pupils." 28

In spite of such criticism, Smellie's simulators continued to be used after his death, although their ultimate fate is unknown ${ }^{29}$. It is important to note that Smellie's method of teaching midwifery was not restricted solely to using simulators. In addition to using detailed charts and drawings, he also used preserved fœtuses and female cadavers ${ }^{30}$. Smellie's use of simulators was not unique at that time, since there were contemporary physicians and practitioners who both designed and employed simulators for instructing midwives. One of the most notable of these was Sir Richard Manningham (1690-1759). Although extensive descriptions of his device are lacking, it seems to have been similar in both construction and purpose to Smellie's simulators ${ }^{31}$.

\section{Other simulators for obstetrics}

Although simulators of this sort continued to be used for some training in obstetrics, they did not gain widespread use during the remainder of the eighteenth and throughout most of the nineteenth centuries. Cost, reluctance to adopt new methods of instruction, skepticism that what was learned from a simulator could not be transferred to actual practice, are some of the factors that likely contributed to the limited use of obstetric simulators. There is evidence to show that obstetric simulators were used when there was an apparent need of them. For example, an American physician, Dr. Richard A. F. Penrose (1827-1908), used a simulator to teach childbirth techniques ${ }^{32}$. Penrose's manikin, which was called Mrs. O'Flaherty, was likely similar to those designed by Smellie, although the lack of a detailed description precludes further comparison.

There was a great need for Penrose's simulator, since social considerations of the time discouraged most medical students (the majority being male) from attending an actual birth. Cianfrani believes that the result of 
this situation was that most medical students of the late nineteenth century graduated without receiving any direct experience with childbirth ${ }^{33}$. Although the fidelity of Penrose's simulator did not equal that of an actual birth, the use of the simulator would provide medical students with at least some experience with birthing techniques and with some of the related complications.

The need for simulators to assist with the general teaching of obstetrics has been diminished by the development of technologies such as cinematography and television coupled with the gradual elimination of unskilled midwives and the relaxation of some traditional social taboos. Training in some specific obstetrical procedures, especially those that could pose an undue risk to the fœetus or the mother if they are performed incorrectly, may still require the use of simulators. In consequence, many modern simulators are designed to provide practice in specific obstetrical procedures. An example of such a simulator is one intended to assist nurses and midwives in mastering the skill of attaching scalp electrodes to a fœtus in utero. The device, formed of plastic primarily and marketed by the United Kingdom firm of Adam, Rouilly Ltd., consists of a simulation of the lower portion of the female torso. Inside, a cervical canal, dilated os and a simulated fœtal head are provided. The device is further equipped with electronic sensors that are connected to a control console. The console indicates whether or not the actions of the user are appropriate. In this manner, the simulator assists the user in developing skill according to accepted procedure. Except for the vagina, the fidelity of the external appearance of the simulator is low. The fidelity of the relevant internal components is high, however, since it is the internal components that are relevant to the particular procedure being simulated $^{34}$.

The earlier obstetrical simulators mentioned previously were intended to provide instruction in basic obstetrical anatomy and in particular procedures. In these instances, an overall high degree of fidelity was considered essential so that the student could transfer the knowledge gained from the simulator to a real situation without difficulty. An implicit assumption with the Adam, Rouilly simulator, therefore, is that the user possesses at least some basic knowledge of obstetrical anatomy and procedure. The use of a simulator in this case is considered desirable since it allows practice without disturbing pregnant women and their fœtuses, or without placing them at risk. There are other areas of modern medicine where simulators are also a most appropriate means of instruction. 


\section{Resuscitation simulators}

Medical personnel as well as the general public are encouraged to become competent to administer mouth-to-mouth ventilation techniques as well as cardiopulmonary resuscitation (CPR). Although it is possible to learn the theory and the principles of these techniques by means of lectures, illustrations and demonstrations, it may be argued that competence in performing these procedures can be gained only through experience. While some practice in mouth-to-mouth ventilation can be obtained by using live participants, CPR cannot because of the risk of harming the participant. Live participants for mouth-to-mouth ventilation practice may not always cooperate properly, so that the experience gained may not be useful in an actual emergency. The risk of passing contagious diseases through bodily contact is another disadvantage in using live participants.

These considerations were among the factors which motivated a Norwegian doll and toy maker, A.S. Laerdal, to develop a line of manikins that would simulate human beings sufficiently to enable them to be used for resuscitation training ${ }^{35}$. Laerdal introduced his manikin, which he called Resusci-Anne, in 1960. It is a life-size representation of a young adult female complete with appendages, hair, a realistic face and clothing. The simulator is largely composed of various plastics, including the skin which is lifelike in both appearance and touch. The first versions of Resusci-Anne were designed to teach mouth-to-mouth resuscitation solely, so the trachea and the lungs are the only internal organs simulated. The fidelity of the internal organs is low, as the airway consists of length of plastic tubing and a plastic bag simulates the lungs. The operation of the simulator, nevertheless, reflects a high degree of fidelity. Unless the head is tilted back sufficiently, for example, the airway will be obstructed by a small bar located inside the manikin's neck. This condition simulates the obstruction of an actual trachea by the tongue. Instructive feedback is provided to the user by means of colored indicator lamps. The lamps comprise parts of electrical circuits which are completed when certain microswitches within the manikin are closed. If sufficient ventilation is being provided, for example, then the circuit connected to the green indicator lamp is completed. In addition, the lung is arranged so that its inflation and deflation cause the chest of the simulator to rise and fall ${ }^{36}$. Although the Resusci-Anne possesses an overall high degree of fidelity, there are several attributes including heart beat, pupillary changes and skin temperature, which are not reproduced by the device. 
In the interest of user safety, there is one attribute that is intended to have low fidelity. In the usual practice of mouth-to-mouth resuscitation, air that has been blown into the lungs of the victim is expelled through the mouth and the nose after the resuscitator removes his or her mouth from the victim. The exhalation of air from the victim indicates that the resuscitation technique is effective. Although the passing of respired air between one individual and another entails the risk of passing certain contagious diseases, the risk is not usually a primary concern of the resuscitator. There is little to be gained, however, by exposing students unnecessarily to such a risk. With this concern in mind, the internal parts of current versions of the Resusci-Anne are designed so that exhaled air from the manikin is exhausted from a port in the side of the chest rather than through the mouth and nose. While this action does not simulate exhalation accurately, it reduces the risk of disease transmission between users via the resuscitation simulator ${ }^{37}$. It may be argued that the low fidelity of this one aspect of the simulator is compensated for by the feedback mechanism.

Later versions of the Resusci-Anne also contain a spring and piston mechanism within the chest cavity to permit CPR techniques to be learned and practiced. The spring and piston mechanism is intended to simulate the resistance of the breastbone and ribcage to being depressed. An indicator lamp array, a paper recording mechanism or an optional computer connection enable the apparatus to provide instructive feedback to the user on whether or not the technique used is effective and to what degree ${ }^{38}$.

In addition to the Resusci-Anne, Laerdal also makes a simulator in the form of a baby, called Resusci-Baby, as well as a simulated youth called Resusci-Junior ${ }^{39}$. Like the Resusci-Anne, the two smaller versions are designed to provide simulations for the purposes of resuscitation and CPR training. The smaller versions are considered important because some adult resuscitation techniques are inappropriate for babies and youths ${ }^{40}$.

While it may seem that most simulators for medical training are designed to have an overall high degree of fidelity, there are a number of simulators produced that are designed to possess a high degree of fidelity only in a few areas, typically those attributes and conditions most associated with the concept being presented. It is intended by the designers and manufacturers of such simulators that they will be used by personnel that are already familiar with general procedures with patients, but who require practice with a particular maneuver on a particular part of the body. 


\section{Intubation and bronchoscopy simulators}

In the case of intubation practice, it is important that the laryngoscope is inserted correctly and without excess pressure on the teeth. In adddition, correct tube placement is essential for the well-being of the patient. Given that the procedure is unpleasant at best for a patient, there is little opportunity for practice. With these factors in mind, most intubation simulators consist of a manikin head with a high fidelity of the external appearance. Depending upon the complexity of the simulator, some either contain a simulation of the trachea while others, designed for practice in bronchoscopy as well, also contain a simulation of the nasal passages. Most models are also equipped with a battery-powered indicator lamp that lights if the laryngoscope is pressed against the teeth with excessive pressure. The simulated tracheas of some versions of this type of simulator are fabricated of clear plastic, so that the user can observe the effects of his/her actions as well as providing a visual indication that the intubation tube has been placed correctly ${ }^{41}$.

\section{Infusion simulator}

Another procedure that is difficult to practice on a patient is infusion. To provide such practice, simulated human arms usually fabricated of various plastics have been devised. While the external appearance of these simulators have low fidelity, the simulated veins and the movement of colored fluid through them have high fidelity. It is possible, with such a simulator, for an individual to gain practice both in injection techniques and in the introduction of intravenous cannulæ $æ^{42}$. By using colored fluids with this simulator, the user receives immediate feedback as to whether or not the injection was successful or whether the intravenous cannula is positioned correctly.

\section{Simulators for cardiology}

One area in medicine that seems to use more simulators than any other is cardiology. The use of simulators appears to be prevalent in two main areas, training in defibrillation techniques and in diagnosis. In both areas, actual patients are not suitable either for practice or for providing examples of all 
possible conditions a cardiologist might encounter. For defibrillation training, like training in intubation and infusion, a simulator is required, since it is dangerous to practice the procedure on a healthy patient, and to practice the procedure on a patient with a fibrillation may place that patient in greater peril. Simulators for practice in defibrillation do not require an overall high level of fidelity. The area of the chest must possess high fidelity so that the user will be able to transfer what has been learned on the simulator to an actual patient when required to do so. Some simulators for practice in defibrillation consist of an artificial torso, while others consist of an entire manikin. Internal fidelity is usually low, since these simulators usually contain electronic sensors to relay the position of the defibrillation paddles to the control unit or monitor ${ }^{43}$. The simulator may simply provide feedback on paddle placement, or if the device is complex enough, it may simulate a variety of fibrillations that require slightly different techniques. Most of the more complex simulators are controlled by a computer. The use of computer-controlled simulators, however, is greatest in the area of cardiac diagnosis.

To be sure, there are simulators for training and practice in cardiac diagnosis that are simple enough not to be controlled by computer. One example is a device called the Heart Sound Generator manufactured by Cardionics Incorporated. The device consists of a specialized reader/player that interprets areas of light and dark on rotating disks made of lithographic film. The disks, which are interchangeable, are installed in a similar fashion to phonograph records on an ordinary audio disk player. Instead of a tone arm, the heart sound generator employs a fixed light source and a series of photo-electric cells to interpret the information contained on the disks. They contain representations of particular cardiac dysfunctions that are simulated on a sound amplifier as well as visually on a cathode-ray display. The device also contains a series of controls by means of which the operator can increase or decrease the volume of a particular sound track. In this manner, a student can be acquainted with a particular sound of a dysfunction which would otherwise be difficult to discern from the background sounds. The relationship between the sound of a particular condition and its ECG may also be established. A student may also gain experience in identifying and diagnosing particular dysfunctions, especially those that are not likely to be encountered readily in normal clinical practice. The simulator can also serve as a test unit to enable instructors to ascertain how well their students can differentiate both heart sounds and electrocardiogram traces. 
Although the heart sounds and the electronic trace are reproduced faithfully, the remainder of the simulator bears no resemblance to a human patient at all. The pedagogical premise employed is that the user is already familiar both with the rudiments of cardiac examination and with basic interpretation of heart sounds and traces, and that the only information to be learned from the simulator is the identification and recognition of particular dysfunctions. There is no need, therefore, for additional elements of the simulator to possess high fidelity, since a medical practitioner would be able to transfer the knowledge gained on the simulator to a clinical setting. It may be argued further that by including other elements in such a simulator the attention of the student would not be focused entirely upon the primary concept being presented. While there are usually many distractions in an actual clinical setting, the pedagogical approach of this type of simulator is to instruct the student in an environment free of non-essential distractions so that accurate discrimination of different murmurs can be made. Once the material is learned, it follows that the student will be able to diagnose particular cardiac dysfunctions while being able to contend with a number of distractions. Although this progression may seem logical, the efficacy of this method of instruction is not accepted universally. ${ }^{44}$ Nevertheless, many simulators in medicine operate from the premise that to instruct effectively, the information to be learned should be presented without most of the accompanying stimuli in the process or procedure. As mentioned previously, there are simulators that consist of images and sounds generated or controlled entirely by computer.

\section{Computer-generated and computer-controlled simulations}

The adaptation of computers to teach new material or to assist with instruction became practical during the late 1950s. ${ }^{45}$ While a valid pedagogical application of computers is simulation, they are also used for problem solving, drill and practice, games, simple information presentation and tutorial instruction. ${ }^{46}$ Currently the most common means by which a computer presents information to a human being in a comprehensible fashion is through a video monitor. Devices that enable the computer to present information to human beings are usually called output devices. Sound systems, optical projectors and printers are other common output devices. Their ready availability, coupled with high costs of developing custom 
output devices mean that most computer-based simulations employ output devices which, by their nature, possess a low degree of fidelity. This does not mean that such computer systems are inappropriate for medical education. In a manner similar to the heart sound generator, most computer-based simulations presume a given level of knowledge or competence in the area being instructed. A cardiology computer program, for example, may display a drawing of a patient on a video monitor and ask where one would place a stethoscope in order to best hear the effects of a mitral stenosis at the apex. ${ }^{47}$ The design of the program assumes that the student knows what a stethoscope is and how to interpret the sound it picks up. In this particular program, the stethoscope consists of a light pen (a specialized input device) that indicates selected positions on the monitor to the computer. The computer, in turn, either indicates to the student that the stethoscope has been placed in an inappropriate position, or it will cause a recording of the heart sound, as recorded in that location, to play. ${ }^{48}$ While the overall fidelity of the simulator is low, the concepts that are to be learned, namely the correct placement of the stethoscope and the correct differentiation of various cardiac dysfunctions, possess high fidelity. While there is some debate as to whether or not this method of instruction is as good as or better than traditional methods, it is inappropriate for providing instruction in procedures where certain manual skills are required. ${ }^{49}$ Students usually gain experience through clinical practice, but it is possible that while mastering a particular skill some patients might suffer discomfort and unnecessary injury. To avoid such problems, other types of simulators have been developed to enable the student to gain particular skills without placing live patients in pain or at risk.

\section{Simulators with variable fidelity}

It was mentioned previously that manikin-based simulators have been designed to assist lay people to learn particular life-saving skills. Other manikin-based simulators have been developed to faciliate skill-development among medical practitioners primarily. While most models of this type are equipped with a simple feedback mechanism, it is possible to connect some feedback mechanisms to computers so that more complex medical conditions can be presented and analyzed. For example, Gaba and DeAnda have connected an intubation manikin to several computers so that anæs- 
thesia procedures can be simulated. In addition to evaluating intubation technique and vital signs, the arrangement also simulates gas flow and urine production in response to the user's actions..$^{50}$

Although the physical appearance of the simulated patient has not changed in this case, the fidelity of the simulation has been increased, since the computer can present additional conditions that would be present with a live patient. This shift to a higher level of fidelity reflects a pedagogical theory: by ieplicating actual conditions, potential problems can be overcome before live patients are encountered. ${ }^{51}$ Furthermore, this type of simulation is also well-suited both for the testing of new techniques and for evaluating the skill of practitioners. It seems that the underlying premise of this type of simulation is that the greater the level of fidelity of the simulation, the greater the likelihood is of knowledge being transferred from the simulator to live patients. This premise may be the primary reason why high-fidelity simulators for medical education have been devised.

\section{High-fidelity simulators}

A high-fidelity simulator may be defined as a device that attempts to reproduce an actual object or event at the highest degree of fidelity possible with given technology. Some common examples include specialized flight trainers, such as those which emulate the control cabins of Boeing 747 Jumbo jet aircraft. Unlike simpler flight simulators, which normally use large video monitors to display the cockpit as well as the remainder of the simulation, high-fidelity flight simulators attempt to reproduce attributes such as noise, vibration and gravitational forces. In such instances, the layout of the cockpit as well as other relevant stimuli and sensations make a situation practically identical to the experience in a real aircraft. In a similar fashion, high-fidelity simulators designed for medical applications attempt to replicate the actual object or situation exactly.

\section{Sim One - a simulator for ancesthesiology}

One of the first high-fidelity simulators to be developed for use in medical education is referred to as Sim One. This device, constructed during the late $1960 \mathrm{~s}$, combines the technology of medical manikins with the extensive control afforded by a computer. Sim One consists of a plastic-skinned 
manikin body which is intended to represent an adult male of indeterminate age with a height of six feet and a weight of 195 pounds. ${ }^{52}$ Unlike the manikins designed for resuscitation training, which have fidelity in only a few areas, Sim One is similar to an actual patient in many ways. In addition to possessing a heart beat, pulse and blood pressure, Sim One also breathes, opens and closes its mouth, opens and closes its eye lids, exhibits pupillary changes and can receive injections of anæsthetics to which it will react. A computer interprets the actions of the student on the manikin through means of subcutaneous sensors which are specialized input devices. Once the entering information is interpreted, the computer causes the manikin to react according to instructions in its program. For correct procedures, the manikin reacts in what is considered a normal fashion, the eye lids close and muscles relax. Incorrect procedures result in a variety of adverse reactions which can include an emulation of death. Why would such an instructional device be necessary?

Gravenstein notes :

"In anesthesia, the patient suffers the consequences of mistakes made by the student". ${ }^{53}$

Although there is little likelihood that a student who is properly supervised will make a serious mistake, there is little to be gained by exposing a patient to such a risk. At least one study has been made concerning the efficacy of Sim One versus internship instruction. Abrahamson, Denson and Wolf find that the effectiveness of Sim One is only slightly higher statistically than conventional methods of instruction. The major advantage noted is that a student will learn the required skills in a shorter time interval thant if he/she was instructed through existing methods. ${ }^{54}$ The use of a high-fidelity simulator would also ensure that each student receives both exposure to and practice in those conditions and procedures that are considered important before being permitted to practice upon real patients.

\section{Harvey - the heart patient}

Gordon describes the development of a manikin-based device that can emulate most conditions and symptoms exhibited by patients with cardiologic disorders. ${ }^{55}$ Based somewhat upon Sim One, a prototype cardiology patient simulator was completed in $1976 .{ }^{56}$ Called Harvey, the device incorporates additional realistic attributes such as the greying of the hair and skin 
cyanosis. ${ }^{57}$ It is important to note that Sim One was intended to possess cyanosis initially, but time and the constraints of existing technology precluded these elements. ${ }^{58}$ Through the use of multi-tracked recording tapes, a small radio transmitter, modified stethoscopes that can selectively receive broadcast radio signals and special sensors positioned strategically within the manikin to activate the reception of the stethoscope, normal heart sounds as well as up to 50 abnormal sounds can be produced. ${ }^{59}$ By increasing the overall fidelity of the simulator to the highest level possible, certain disease conditions that are associated with particular age groups can be reproduced with great accuracy. By having the manikin emulate an older person with grey hair, for example, it is possible to reproduce the symptoms and the effects of a stroke in a realistic manner.

It may be argued that high-fidelity simulators have many advantages for instruction over the use of live patients. Such advantages include: no risk of death; the presentation of rare diseases and conditions that might not normally be encountered by a medical student; procedures can be halted and repeated; traumas can be emulated in real time, or they can be slowed down for closer study. ${ }^{60}$ An evaluation comparing the skill levels of cardiology students trained by Harvey with the skill levels of students trained by traditional methods reveal that students who were trained on the highfidelity simulator achieved significantly higher scores. ${ }^{61}$ In pedagogical terms, high-fidelity simulators more so than low-fidelity simulators, such as the depiction of a patient on a video monitor, force students to interact with the material being learned. High-fidelity simulators eliminate most of the problems that are associated with transferring what has been learned in the classroom, or some other environment removed from the patient, to practical application. High-fidelity simulators provide a convenient means to enable practicing physicians to keep up with new techniques in diagnosis and treatment. Perhaps the most important advantage of using a highfidelity simulator is that it tends to ensure a standard level of instruction that might be lacking if a student received clinical experience only. ${ }^{62}$

There are factors which diminish the appeal of high-fidelity simulators. A major one is cost. It may be argued that a high initial capital cost is justified given the large number of students that the apparatus can train before it either wears out or becomes obsolete. ${ }^{63}$ Some medical institutions, however, may not be able to raise sufficient capital to purchase a high-fidelity simulator in the first place. Failure of the apparatus and maintenance costs are additional disadvantages. While high-fidelity simulators are common in 
aviation, high-fidelity patient simulators are generally scarce in medicine, and so availability of parts and competent service may prove to be unstable. Also, the use of a high-fidelity simulator does not eliminate the need for live patients for student practice, since an interactive clinical component is usually considered essential. This need for live patients compounds the difficulty in justifying the purchase of a high-fidelity simulator. It should be noted, however, that it is not always possible to find suitable patients for students, even in some large teaching hospitals. ${ }^{64}$ Another concern is whether the device actually embodies conditions and diseases that are widely important, or whether it reflects a local bias towards particular conditions and diseases. ${ }^{65}$ Although the disadvantages of simulators may induce institutions to not use them, a high demand for new physicians coupled with rapidly-changing treatment techniques that must be learned quickly by practicing physicians, may result in an acute need for such instructional devices.

\section{Conclusions}

Simulators have had minimal rôles throughout most of the history of medical education. While technological limitations appear to be the most significant factor in their scarce use, particular social considerations required the development of alternate methods of pedagogy to those in use. From the examples described above, it is apparent that the application of simulators to this field has been valid and effective. The pedagogical foundations of these devices is sound, although the variability of fidelity may determine the extent to which a particular device is used. In the case of obstetrical training for example, simulators arose from a perceived need for a satisfactory training method to contend with an immediate need for competent midwives. Given the developments in this technology within the last fifty years, it is possible that the use of simulators will increase in the future, should the need arise to teach new concepts and procedures at set times to large groups of individuals. Although factors such as cost may restrict the use of some high-fidelity simulators, other factors such as the efficacy of the devices as well as the satisfaction of an immediate need should not be overlooked. Simulators may indeed play a more significant rôle in medical education of the future. 
Notes

1 Stephen M. Alessi and Stanley R. Trollip, Computer-based instruction: Methods and development, Englewood Cliffs, New Jersey, Prentice-Hall, Inc., 1985, pp. 161-193.

2 Ibid., pp. 185-186.

3 Albert H. Buck, The growth of medicine: From the earliest times to about 1800, New Haven, Connecticut, Yale University Press, 1917.

4 Albert Bandura and R. H. Walters, Social learning and personality development, New York, New York, Holt, Rinehart and Winston, 1963, pp.44-67.

5 Alessi \& Trollip, op. cit., note 1 above, pp. 134-135.

6 Burrhus F.Skinner, "The science of learning and the art of teaching". Harvard Educational Review, 24: 86-97, 1954.

7 See: Cicero, De re publica, trans. C. W. Keyes, London, William Heinemann, 1928, 1. 14.2122 ; Cicero, De natura deorum, trans. H. Rackham, London, William Heinemann, 1933, 2.61. 153-154; Cicero, Tusculan disputations, trans. A.E. Douglas, Warminster, Bolchazy Carducci Publishers, 1985, 1.63-64.

8 Buck, op. cit., note 3 above, pp. 243-258.

9 See George Blaine, "Biological teaching models and specimens", Lancet, 261 : pp. 337-340, 1951 ; and Rumy Hilloowala and Joseph Renahan, "XVIII century anatomical models at La Specola, Florence,", Anat Anz, 159: pp. 141-158, 1985.

10 E.M. Jameson, "Gynecology and obstetrics," Clio Med, $17:$ 35-37, 1936.

11 Buck, op, cit., note 3 above, pp. 553-555.

12 Jameson, op. cit., note 10 above, pp. 36-43.

13 H.Speert, Iconographia gyniatrica : A pictorial history of gynecology and obstetrics, Philadelphia, Pennsylvania, F. A. Davis, 1973, pp. 70-71.

14 Jameson, op. cit., note 10 above, p. 31.

15 William R.Smellie, $A$ treatise on the theory and practice of midwifery, 2 vols., ed A. McClintoch, London, The New Sydenham Society, 1876, 2, 14. See also R. W. Johnstone, William Smellie, the master of British midwifery, Edinburgh, E. \& S.Livingstone, 1952, p. 18.

16 Smellie, op. cit., note 15 above, p. 14.

17 John T. Schlebecker, "Farmers and bureaucrats: Reflections on technological innovation in agriculture," Agricultural History, 51 : 650, 1977.

18 Jameson, op. cit., note 10 above, p. 49.

19 Smellie, op. cit., note 15 above, 2, 14.

20 Ibid., pp. 13-14.

21 Jameson, op. cit., note 10 above, p. 49.

22 Johnstone, op. cit., note 15 above, p. 18.

23 Smellie, op. cit., note 15 above, 2, 14.

24 Johnstone, op. cit., note 15 above, p. 25.

25 Ibid., p. 26.

26 Ibid., p. 25.

27 P. Findley, The priests of Lucina: The story of obstetrics, Boston, Massachusetts, Little, Brown, 1939, p. 171.

28 Johnstone, op. cit., note 15 above, p. 26. 
29 Ibid., p. 28.

30 Ibid., p. 26.

31 H. R.Spencer, The history of British midwifery from 1650 to 1800, New York, New York, AMS Press, 1978, p. 16.

32 T. Cianfrani, A short history of obstetrics and gynecology, Springfield, Illinois, Charles C. Thomas, 1960, pp. 394-395.

33 Ibid., p. 394.

34 Adam, Rouilly Ltd., "Instruction aid," Midwife Health Visitor \& Community Nurse, 24 : 384 .

35 A. S. Gordon, A death mask to help save lives: The story of Resusci-Anne, Armonk, New York, Laerdal Medical Corporation, n.d.

36 A. A. Seireg, "Meeting the manikin with the death mask," Soma: Engineering for the human body, $2: 12-13,1987$.

37 A.D. Hudson, "A hypochlorite solution for removing bacteria from CPR manikins," Ann Emerg Med, 12: 485-488, 1983.

38 A.C.Pinchak, D. E. Hancock, J. F. Hagen, F. B. Hall, "The chest wall dynamics of CPR: What works," Soma: Engineering for the human body, 2: 6-17, 1987.

39 Laerdal Medical, Resuscitation training aids and emergency equipment catalog, Armonk, New York, Laerdal Medical, 1989.

40 Seireg, op. cit., note 36 above, p. 12.

41 Laerdal Medical, Laerdal airway management trainer, information sheet, Armonk, New York, Laerdal Medical, 1989.

42 Laerdal Medical, op. cit., note 39 above, p. 9.

43 A. P. Spivack and D. K. Miller, "The arrhythmia trainer," Journal of the American Medical Association, 202 : 151-153, 1967.

44 D. M. Gaba and A. DeAnda, "Anesthesia simulation in an actual operating room environment," Anesthesiology, 67: A467, 1987. In addition see, V.A.Sandoval, R.A.Dale, W. D. Hendricson, and J. B. Alexander, "A comparison of four simulation and instructional methods for endodontic review," J Dent Educ, 51 : 532-538, 1987.

45 G. J. Rath, N.S.Anderson, and R.C.Brainerd, The IBM research center teaching machine project, in E. H. Galanter (ed.), Automatic teaching: The state of the art, New York, New York, John Wiley \& Sons, 1959.

46 Alessi and Trollip, op. cit., note 1 above.

47 Richard E. Rossall, Computer-assisted learning in an undergraduate M.D. cardiology program, Edmonton, Alberta, Division of Educational Research Services, University of Alberta, p. 10, 1974.

48 Ibid., pp. 10-12.

49 V.A.Sandoval, R.A.Dale, W. D. Hendricson, and J.B. Alexander, op. cit., note 48 above, pp.532-538.

50 Gaba and DeAnda, op. cit., note 44 above.

51 Ibid.

52 J.S. Denson and S. Abrahamson, "A computer-controlled patient simulator," JAMA, 208 : 504, 1969.

53 J. S. Gravenstein, "Training devices and simulators," The Journal of Anesthesia, 69: 295, 1988. 
54 S.Abrahamson, J.S.Denson and R.M. Wolf, "Effectiveness of a simulator in training anesthesiology residents," J Med Educ, 44: 517-518, 1969.

55 M.S.Gordon, "Cardiology patient simulator: Development of an animated manikin to teach cardiovascular disease," Am J Cardiol, 34 : 350-355, 1974.

56 M.S.Gordon, G. A. Ewy, A. C. DeLeon Jr., R. A. Waugh, J. M. Felner, A. D. Forkner, I. H. Gessner, J. W. Mayer, and D. Patterson, "Haryey, the cardiology patient simulator: Pilot studies in teaching effectiveness," Am J Cardiol, 45 : 791-796, 1980.

57 Gordon, op.cit., note 55 above, p. 351 .

58 Denson \& Abrahamson, op. cit., note 52 above, p. 505.

59 Gordon, op. cit., note 55 above, p. 352.

60 Ibid., p. 353.

61 G.A.Ewy, J.M. Felner, D. Juul, J.W. Mayer, A. W.Sajid, and R.A. Waugh, "Test of a cardiology patient simulator with students in fourth-year electives, J Med Educ, 62: 738$743,1987$.

62 Gordon, Ewy, DeLeon Jr., Waugh, Felner, Forkner, Gessner, Mayer, and Patterson, op. cit., note 60 above, p. 795 .

63 Gordon, op. cit., note 55 above, p. 354.

64 Gordon, Ewy, DeLeon Jr., Waugh, Felner, Forkner, Gessner, Mayer, and Patterson, op. cit., note 60 above, pp. 793-795.

65 Gordon, op. cit., note 55 above, p. 354. 


\section{Zusammenfassung}

\section{Die Entwicklung von Simulatoren für den medizinischen Unterricht}

Simulatoren erlauben Lernen und Üben ohne Belästigung oder gar Gefährdung von Patienten. Sie treten schon gegen 1700 in Erscheinung mit dem geburtshilflichen Phantom der beiden Grégoire in Paris. Die Entwicklung geht über den raffinierten geburtshilflichen Simulator von Smellie bis zu Modellen unserer Zeit mit hochspezialisierten Funktionen. - Seit 1960 finden Simulatoren zunehmend Verwendung zur Ausbildung von Ärzten und Laien in der Technik der Wiederbelebung. In Verbindung mit der Computertechnik ist die Schaffung von High-FidelitySimulatoren möglich geworden: künstliche Patienten, die z.B. auf Anästhetika lebenstreu reagieren. Den Simulatoren dürfte in Zukunft wachsende Bedeutung im klinischen Unterricht zukommen.

\section{Résumé}

\section{Le développement des simulateurs pour l'enseignement médical}

Les simulateurs permettent d'apprendre et de s'exercer sans inconvénient ni danger pour le patient. Ils apparaissent déjà vers 1700 avec le mannequin obstétrique des deux Grégoire à Paris. En passant par le simulateur obstétrique raffiné de Smellie, leur développement va jusqu'aux modèles d'aujourd'hui à fonction hautement spécialisée. - Depuis 1960, les simulateurs sont de plus en plus utilisés pour la formation des médecins et des non-professionnels dans les techniques de réanimation. En liaison avec la technique des ordinateurs, la création de simulateurs high fidelity, surtout pour l'anesthésiologie et la cardologie, est devenue possible. Les simulateurs devraient acquérir à l'avenir une importance croissante dans l'enseignement clinique.

\section{George H. Buck}

University of Alberta

Centre for Research in Applied Measurement and Evaluation

Faculty of Education

3-104 Education Building North

Edmonton

Canada T6G 2G5 